\title{
Global research initiatives in geosciences and something else
}

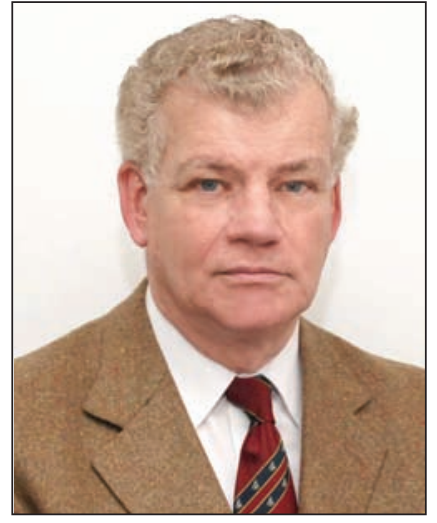

Our Union is now deeply involved in helping to define appropriate global research initiatives. This endeavor is an outgrowth of the International Year of Planet Earth (IYPE) - an important IUGS initiative of the last few years. Toward the end of IYPE the creation of a planning group was proposed to develop a global platform or 'World Geosciences Forum' and to define a limited number of worldclass scientific projects along with a feasible business and funding plans for them. The idea is to further develop and implement the 2008 Tsukuba Declaration, which was endorsed by the IYPE, the International Polar Year-IPY, the International Heliophysical Year IHY, and the Electronic Geophysical Year-eGY. (See the note at the end of this Editorial for more information about the Tsukuba Declaration).

In this context, when we look to important projects for research in the geosciences, we are constrained by the need to address issues that are of direct and immediate relevance to society. Examples are the relationship of humankind with the environment, including climate change, and the growing need for strategic resources, chief among them being water.

There are, however, other important issues to be evaluated. One is the fact that the problems and needs of various countries and world regions are quite different. Another issue is related to the fact that because of differences in economic development, education and capacity building also differ substantially throughout the world. Because of all these differences it becomes more difficult to choose among possible global projects. Some may be quite useless because they cannot be applied to specific circumstances. What is then needed is a major emphasis on a more complex approach that, on one side, includes projects adapted to the diverse circumstances the Earth sciences are facing in different regions of the world and, on the other, will provide a common ground for a collaborative strategy.

A collaborative strategy is perhaps what should be first considered and discussed in detail, because not only do we need to undertake global research initiatives but also we need to build the common ground on which these initiatives should be developed. This common ground should consists of interdisciplinary approaches, international cooperation, evidence-based decision making on national and international levels, and sharing of scientific knowledge to reduce the gap between developed and developing countries. In summary the "something else" mentioned in the title of this Editorial.

The basic question is: How can the efforts of the world geosciences community be coordinated to promote any possible world-class science project?

The first tool that comes to mind for achieving this goal is the existing international organizations, which collectively encompass most of the geoscientific community around the globe. These organizations are quite different in scope and size, but the ones that really matter are those with an effective presence on the international scene.

Let us first consider the eight GeoUnions within ICSU, i.e. the International Astronomical Union (IAU), the International Geographical Union (IGU), the International Union for Quaternary Research (INQUA), the International Society for Photogrammetry and Remote Sensing (ISPRS), the International Union of Geodesy and Geophysics (IUGG), the International Union of Geological Sciences (IUGS), the International Union of Soil Sciences (IUSS), and the International Union of Radio Science (URSI). This informal consortium originated within ICSU during the last ten years. The group has formalized a positive relationship that is used to work within ICSU: taking a common position on formal issues related to ICSU's organization and activities, such as the nomination of people to key ICSU bodies, supporting grant applications for specific research projects, etc.

But, is this enough for what the geosciences need globally? It is evident that much more is needed, especially when we consider the difficulties of addressing even a seemingly simple request such as the one made to the IUGS in the last year by the IUGS German National Committee and the EuroGeoSurveys. They asked that IUGS explore the possibility of developing with the IUGG a way to coordinate planning for major meetings. The next IUGG General Assembly (Melbourne, 2011) and the next International Geological Congress (Brisbane, 2012) will be closer than ever in time and place. The EuroGeoSurveys have also suggested that merger of IUGS and IUGG be explored.

Problems are not limited to the interactions among the GeoUnions. Within the working structure of each Union there are entities that must interact with each other. The fact is, that organizations are quite different in scope and size, their activities often overlap, and communication among them and with other international bodies is frequently not optimum. In addition, almost everyday a new entity or initiative is created to deal with problems that in some way or other are already a part of the activities of existing organizations. Difficulties of interaction and duplication of efforts are further exacerbated by the fact that in most of these organizations the officers of the governing bodies change with various periodicities, work adhonorem, and come from different backgrounds; furthermore, there is usually no permanent executive staff. As a result the long-term planning and effective management required in today's world are very difficult to achieve. This situation stems in part from the fact that most of these organizations were created many years ago, when global communications and circumstances were completely different. Additionally, the changes introduced to them since their founding have not been sufficient to keep up with the developments of human society.

In summary, there are many internationally established organizations with different scopes and structures, some of which supplement each other, while some others duplicate activities and efforts, and in general without any long-term coordinated planning. 
The question and challenge is how to get all these organizations working together effectively in a world-class scientific project. The main goal would be to achieve better coordination and to work toward greater efficiency and relevance, while reducing the existing duplications of functions and efforts.

One of the possible avenues for enhancing coordination is the merger of some organizations. This was done recently at the national level in France by the Comité National Français de Géologie, the Union Française des Géologues, and the Société Géologique de France. For large organizations like IUGS and IUGG, however, the possibility of merger is more difficult, if not impossible, because of their sizes. Furthermore, merger might lead to a more complex and probably less efficient organization. In any circumstance and whatever the structure or structures involved, both organizations should study the possibility of attaining better integration of activities.

Thus, at the last meeting of the International Geological Congress Committee (IGCC) held in Brisbane on June 25, 2010, it was decided to propose to the IUGG the formation of a task group to analyze the coordination of IGC and IUGG General Assemblies. This will probably require a modification of the statutes of the organizations. Modification of the IGC and IUGS statutes is currently underway. This surely represents an opportunity to go beyond cosmetic changes to work out some substantial changes that will improve the working structure of our Union, opening the way, perhaps, for more participation of affiliated organizations and some type of permanent management structure. In parallel, the IUGS has recently created a Strategic Planning Committee to produce a new strategic plan, and at the GeoUnions last meeting in Paris on April 2010, IUGS proposed developing a common GeoUnions strategic plan.

All these actions could open the possibility of introducing the major changes needed to attain a better coordination of the bodies that serve the international geoscientific community. But the question is: Coordination for what? As I have stated above, we need more than global research initiatives: we need to build the common ground on which these initiatives should be developed. In this regard, priority areas to be considered are geoeducation, capacity building and transference, and sharing of scientific knowledge.

There are already three promising initiatives that appear to be on the right track: OneGeology, UNESCO's Earth Sciences Education Initiative on Africa and the Global Geosciences Workforce.

One Geology involves the participation of Geological Surveys around the world in the integration of data in standard format within a dynamic web portal. At the same time the Geological Surveys are coordinating efforts within broad regional organizations such as the EuroGeoSurveys and the Association of Ibero-American Geological Surveys.

UNESCO's Earth Sciences Education Initiative on Africa, aims to promote research projects, exchange of scientists, and development of centers of excellence. This promising initiative incorporates participation of organizations such as IUGS, the Geological Society of Africa (GSAf), the Commission for the Geological Map of the World (CGMW), the International Centre for Training and Exchanges in the Geosciences (CIFEG), the African Association of Women in Geosciences (AAWG), and Museum of Central Africa.

The Global Geosciences Workforce was proposed by the American Geological Institute, formally established by IUGS, and has the support of UNESCO. Goals of this initiative include establishing definitions of comparability of data and information regarding the jobs, education, fields, and international mobility of geoscientists; determining a global baseline of the quantity and diversity of the geosciences workforce; and identifying capacity-building strategies for a durable global competency in the Earth sciences.

In conclusion, to address with success any geoscientific project of global significance, it is necessary not only to agree on a project but also to improve coordination among international organizations. This improved coordination should basically be focused in geoeducation, capacity building and transference, and sharing of scientific knowledge.

\section{Alberto C. Riccardi \\ President IUGS}

Note: On November 13, 2008, participants of the four "IGY + 50" programs - IYPE, IPY, eGY, and IHY - issued the Tsukuba Declaration. In summary, they looked forward "to enhanced cooperation among the global science community, national academies of sciences, research funding agencies, industry, national governments, and inter-governmental bodies so that society and its leaders will have at their disposal the best possible data and information to make the decisions necessary for a sustainable future for humankind." The complete declaration can be found at www.gsj.jp/iype/en/ docs/decTsukuba_en.htmal 